\title{
WALter ISAaCson (2011) SteVe Jobs
}

\author{
Nelson Zagalo \\ Universidade do Minho, Portugal; nzagalo@ics.uminho.pt
}

Para quem acompanhou a informática nas últimas três décadas, a Apple sempre fez parte do nosso imaginário. Para quem sempre se interessou pela animação, e em especial a animação 3d, a Pixar sempre fez parte do nosso imaginário. Ler este livro é revisitar todo esse imaginário, é preencher espaços com informação desconhecida, é construir uma visão mais alargada e aprofundada destes dois universos. É entrar adentro da essência destas duas marcas culturais da nossa contemporaneidade. Porque conhecer Jobs, é conhecer o seu trabalho, o seu legado.

Apesar das críticas, o livro está repleto de detalhes, provenientes de centenas de entrevistas que nos permitem compreender melhor quem era Steve Jobs. Isaacson procura manter a distância, ser imparcial. Mas é verdade que os factos dificilmente nos poderão deixar indiferentes. Aquilo que Jobs conseguiu realizar durante apenas uma vida, impressiona. E por muito que não gostemos da sua quase dupla personalidade, que por vezes na leitura do livro chegamos a poder categorizar mesmo de bi-polaridade, este relato da vida de Steve Jobs mostra-nos que para ele nunca existiu meio-termo, não houve lugar para o "polite", nem para o protocolo. Para Steve Jobs tudo e todos podiam ser definidos apenas de duas maneiras, "totally shit" ou "brilliant", e foi esta sua peculiar forma de lidar com o mundo que gerou a maior parte dos seus problemas, e que ainda hoje levanta muitos ânimos contra ele.

Por outro lado, podemos especular sobre o facto de este comportamento estar na raiz de tudo aquilo que ele conseguiu. Porque do que podemos percepcionar da leitura, não existiria hoje a Apple sem esta atitude, assim como talvez não existisse a Pixar. Com esta abordagem Jobs conseguiu reunir à sua volta os melhores dos melhores, aqueles que ele denominava de "A players", e era totalmente intolerante para com quem não conseguisse estar a esse nível. A sua "visão do mundo distorcida" como muitas vezes é referenciada no livro, permitia-lhe não ter complacência por quem não trabalhava na sua longura de onda, e ir em frente mesmo quando mais ninguém acreditava que fosse possível. Por isso, se hoje podemos experienciar o Macintosh (1984) ou Toy Story (1995) é talvez porque que o seu criador trilhou um caminho, e dele nunca se desviou. Cada uma das suas invenções, teve um tremendo impacto directo nas suas indústrias, mas não só, o seu impacto foi tão forte que as ondas fizeram mudar muita da indústria à sua volta ao ponto de mudar comportamentos e atitudes em toda a sociedade.

A base do trabalho de Jobs foi a busca pela essência do Design Puro. Como diz Morozov (2012) "the cult of the designer is the foundation of Apple's secular religion". E claramente que este culto o deve também, como diz o Morozov à "functionalist ideology of Bauhaus and its successors", e que está espelhado no comportamento e forma de estar na vida de Jobs como tão bem é descrito no livro do Isaacson. Jobs desenvolveu a partir das ideologias da Bauhaus, um gosto refinado pelo minimalismo funcional, que aplicou 
em todas as dimensões da sua vida, desde a íntima, familiar e pessoal à dos negócios e relacionamentos sociais. Tudo em Jobs é fruto de análise cuidada, profundamente reflectida, no sentido de apurar o mínimo denominador e o seu sentido último de utilidade.

Muito do que se critica em Jobs sobre o paradoxo entre a sua defesa de abordagens espirituais Zen e o seu lado materialista na criação de produtos de luxo, acaba por se resumir a esta filosofia minimalista funcional. Do que se pode ler no livro de Isaacson, Jobs não era budista, mas Jobs também não era materialista. Aliás como disse no seu manifesto "Sure, it was great to make a profit, because that was what allowed you to make great products. But the products, not the profits, were the motivation." Jobs queria apenas mudar o mundo, e queria fazê-lo através do design de produtos. Queria com estes simplificar a vida das pessoas, queria que estas compreendessem que poderiam não só ter, mas ser, mais com menos. Todos os seus produtos foram criados tendo por base a mesma visão, dar às pessoas algo poderoso e complexo num formato que fosse fácil e simples de usar, e que por ser complexo não seria passível de se deixar adulterar pelo utilizador, por forma a manter sempre a simplicidade pré-concebida.

Podemos dizer que de certa forma Jobs não só descende do princípio do design minimal e funcionalista da Bauhaus, mas contribuiu para esse modelo no campo da computação, com uma característica que é mais oriunda das artes do que do design, o princípio do objecto final, fechado não alterável pelos seus experienciadores finais. Desde o seu primeiro produto criado com Steve Wozniack, até ao último criado com John Ive, Jobs sempre defendeu que os produtos deviam ser fechados, não deveriam permitir que os utilizadores os pudessem transformar. E esta atitude aconteceu sempre em total contra-corrente com o mundo à sua volta. No início com Wozniack, um genuíno defensor das arquitecturas abertas, do free-hardware e do free-software. Depois com os CEOs da Apple que olhavam para a concorrência e sentiam a Apple isolada no mundo dos sistemas fechados. Tanto que depois do lançamento do Macintosh em 1984, Jobs foi afastado da Apple por não concordar com uma visão dos sistemas computacionais mais abertos. Depois do seu afastamento a Apple afundou-se e uma década depois foi Jobs que veio revitalizar toda a companhia, agora ainda com mais vontade de fechar todos os seus produtos, e a demonstrar totalmente como em apenas uma década conseguiria revolucionar quase todo o mercado do digital com o lançamento do iPod (2001), iTunes (2001), iPhone (2007), App Store (2008) e o iPad (2010).

Na sua ânsia por criar a melhor obra possível, adicionaria outro princípio aos já nomeados - mínimo, funcional e fechado - e também em contra-corrente com o estado vigente, o de não testar os seus produtos. Todos os seus produtos eram desenvolvidos no mais puro secretismo e de acesso vedado aos pequenos grupos que trabalhavam em cada produto. Jobs reunia continuamente com todos os seus trabalhadores e discutia melhoramentos iterativos aos produtos, ouvia e deixava-se influenciar pelos colegas, mas era ele quem tomava todas decisões de um modo totalmente unilateral, e apenas com base na sua preferência individual. Ao contrário de qualquer outra grande empresa, que gastava milhões em estudos de mercado, testes, inquéritos, focus groups, a Apple investia tudo em equipas de pessoas altamente qualificadas, e com perfis que se 
encaixassem nas preferências de Jobs. Produtos como o Macintosh, o iPod, o iPhone ou o iPad foram fruto de uma visão individual ainda que suportada por muitos dos melhores técnicos em cada área de especialidade.

A Apple de Jobs foi um dos maiores empreendimentos artísticos de sempre. Steve Jobs não era um designer, era um artista. Seguiu a Bauhaus em tudo o que o design tinha de arte, mas definiu por completo uma forma de expressão individual através dos seus produtos. O seu legado não é feito de modelos de electrónica, mas de obras claras e definidas, que valem individualmente pelo modo como mudaram comportamentos a uma escala global. As suas obras não foram meros produtos para serem consumidos, mas antes experiências a serem vividas. As suas criações não eram ferramentas, mas obras finais e fechadas, prontas a ser degustadas pelos seus compradores.

Quando hoje usamos um iPad experienciamos de uma forma totalmente diferente o acesso à internet, a leitura de livros, ou a interacção com videojogos. O iPad não é uma ferramenta para criar, como sempre foram os sistemas computacionais até aqui criados, é antes toda uma nova forma de aceder aos mundos digitais criativos. E só o facto de ser totalmente fechada permitiu que se criassem hábitos de aquisição online de produtos criativos como a música, livros, jornais, revistas, filmes, séries, jogos. Existe hoje toda uma indústria criativa que consegue sobreviver porque existe uma plataforma digital capaz de levar a sociedade a valorar um produto digital, tanto como antes valorava esse mesmo produto físico.

Jobs valorou desde sempre, tal como a própria Bauhaus já fazia, a conexão entre a arte e a tecnologia. A Pixar surgiu deste desejo, desta vontade de levar a tecnologia a um expoente capaz de dar ao mundo da animação o melhor do digital. Mas Jobs nunca se deixou levar pelo simples brilho da tecnologia, procurou antes aliar o seu potencial ao que de melhor se podia fazer no campo criativo. O seu objectivo sempre foi o produto final, não o processo, não a tecnologia em si, nem a arte apenas, mas a convergência destas duas componentes. A sua maior sensibilidade criativa passou pelo modo visionário como deu forma à experiência das tecnologias computacionais. Ou seja Steve Jobs foi um dos mais influentes designers no campo do Design de Interacção, um dos campos mais relevantes dos estudos da Interação Humano-Computador (IHC).

O Macintosh de 1984 é a sua primeira grande conquista neste território, e talvez tenha sido o seu maior legado, com um impacto tal que o seu nome ainda hoje se confunde com o nome da própria marca. O Macintosh revolucionou o modo como seria desenhada até hoje a relação entre o utilizador e o computador. Até ao seu aparecimento o utilizador de computadores tinha de ler e aprender manuais inteiros, antes de poder começar a usar um computador. Com o Macintosh foi inaugurado o caminho das interfaces gráficas para os utilizadores (GUI) que faziam uso do rato e do teclado. O utilizador tinha sido libertado da opressão das interfaces de comandos textuais, algo que foi metaforizado de forma brilhante na campanha publicitária com fundo de Orwell.

Durante décadas muitos questionaram a originalidade desta criação, dado esta ser baseada numa máquina anterior, a workstation Xerox Star, comercializada pela Xerox em 1981. E assim à primeira vista poderíamos dizer então que Jobs nada fez e que se 
teria limitado a usar o que já existia. Mas a realidade está longe de ser a preto e branco, mais ainda quando falamos de evolução tecnológica. As interfaces gráficas são bastante anteriores à Xerox, o Star foi apenas um passo intermédio, a base está lá mais para atrás com nomes como Vannevar Bush, Ivan Sutherland ou Douglas Engelbart. Como nos diz Kevin Kelly (2010), as invenções tecnológicas não são algo que possamos atribuir a uma pessoa apenas, existe uma espécie de inevitabilidade tecnológica que empurra o desenvolvimento, que cria as condições para que num determinado momento possam surgir inovações. Ou seja, de todo podemos dizer que Jobs inventou a interação gráfica entre o homem e o computador, mas o que podemos dizer é que foi ele o primeiro a conseguir juntar a tecnologia correta com a interface correta e a levar a mesma a milhões de criativos no mundo. Uma história que se voltou a repetir em 2007 quando criou o iPhone.

Podemos dizer que o livro de Isaacson retrata muito do que foi Jobs, e proporciona-nos uma viagem narrativa através da personagem. Não é um livro com o qual possamos mudar o mundo, mas ajudará a recarregar a inspiração criativa e empreendedora de muitos.

\section{NOTA:}

Partes deste texto foram previamente publicadas no blogue do autor: Virtual Illusion.

\section{REFERÊNCIAS}

Isaacson, Walter, (2011) Steve Jobs, Simon \& Schuster, ISBN: 978-1451648539, pp. 656.

Kelly, Kevin, (2010), What Technology Wants, Viking, ISBN: 978-067022151, pp. 406.

Morozov, Evgeny, (2012), "Form and Fortune. Steve Jobs's pursuit of perfection - and the consequences", in The New Republic (http://www.tnr.com). 